\title{
BRINCAR AO GÉNERO: SOCIALIZAÇÃO E IGUALDADE NA EDUCAÇÃO PRÉ-ESCOLAR
}

\section{Resumo}

Neste artigo, aborda-se a socialização de género na educação pré-escolar. Procurou-se observar como se realiza o processo de socialização de género numa sala de jardim-de-infância em que a educadora frequentou uma oficina de formação em educação de género e cidadania. Acionando uma metodologia de tipo qualitativo, o estudo decorreu numa sala de uma Instituição Privada de Solidariedade Social (IPSS). Os resultados sugerem que a socialização é fortemente marcada pelos papéis de género, o que na sala observada se manifestou de acordo com uma lógica institucional dominante de cariz tradicionalista. A ação e práticas educativas denotam uma sensibilização para as questões do género e da cidadania, mas ainda aquém de uma promoção efetiva.

Palavras chave: Igualdade de género, papéis de género, socialização de género, educação pré-escolar, pedagogia igualitária.

\section{Abstract}

\section{Playing gender: socialization and equality in pre-school education}

The research focused on gender socialization in pre-school. It aimed at observing the process of gender socialization in a class whose educator had recently done a training workshop on gender and citizenship. By triggering a qualitative methodology, the study took place in one pre-school class of a private institution. The results suggest that socialization is shaped according to gender roles, which in the institution studied is connected to a traditional logic. Action and educational practices reflect some degree of gender and citizenship awareness but still far from an effective promotion goal.

Keywords: Gender equality, gender roles, gender socialization, pre-school education, equalitarian pedagogy.

\section{Resumen}

Jugar al género: socialización e igualdad en la educación preescolar

Este estudio trabaja la socialización de género en la educación preescolar. Se buscó percibir cómo se realiza el proceso de socialización de género en una sala donde la edu-

Departamento de Sociologia, Universidade da Beira Interior, Covilhã, e Centro de Investigação e Estudos de Sociologia (CIES-IUL), Lisboa, Portugal

Endereço eletrónico: csbo@ubi.pt

Endereço postal: Faculdade de Ciências Sociais e Humanas, Estrada do Sineiro s/n. 6200-209

Covilhã, Portugal

** Mestre em Sociologia pela Universidade da Beira Interior

Endereço eletrónico: andreia_222@sapo.pt 
cadora había hecho recientemente una formación en educación de género y ciudadanía. Accionando una metodología de tipo cualitativo el, estudio se desarrolló en una sala de una institución privada de solidaridad social. Los resultados indican que la socialización está fuertemente marcada por los roles de género, que se manifestó de acuerdo con la lógica institucional dominante de cariz tradicionalista. La acción y las prácticas educativas denotan una sensibilización sobre las cuestiones de género y de la ciudadanía, pero aún no una promoción efectiva.

Palabras clave: Igualdad de género, papeles de género, socialización de género, educación preescolar, pedagogía igualitaria.

\section{Introdução}

O género e as desigualdades a ele associadas são uma área de investigação central na Sociologia e concentram também muitas iniciativas de intervenção social. Alvarez e Vieira (2014) chamam a atenção para a persistência de estereotipias de género no sistema educativo português, alertando para a contradição inerente entre o papel emancipatório da escola e a persistência de dinâmicas promotoras de assimetrias de género. $\mathrm{O}$ enfoque do nosso problema de investigação foi perceber como se processa a socialização de género numa determinada instituição educativa, onde três educadoras frequentaram uma oficina de formação em Educação, Género e Cidadania ${ }^{1}$ no ano letivo anterior ao estudo. Considerou-se que a frequência desta oficina de formação no ano letivo anterior à nossa investigação representava um contexto interessante para a investigação pretendida.

Com a investigação, pretendeu-se observar como se realiza o processo de socialização de género entre as crianças; perceber qual a atitude da instituição e da educadora em relação ao género e à socialização de género; analisar as práticas educativas quotidianas da equipa educativa numa perspetiva de género.

$\mathrm{O}$ artigo estrutura-se em duas partes, uma primeira, de revisão de literatura, que dá conta da reflexão existente sobre o tema, e uma segunda, de apresentação e discussão da pesquisa empírica, finalizando com propostas para aprofundamento em investigações futuras.

\footnotetext{
Estas formações foram promovidas pela CIG (Comissão para a Cidadania e Igualdade de Género) com o objetivo de divulgar os guiões Educação, Género e Cidadania, publicados por esta instituição para apoio aos e às docentes da educação básica e ensino secundário na promoção de uma educação promotora da igualdade de género. A oficina em questão foi organizada e ministrada pela UBI (Universidade da Beira Interior) no âmbito do seu plano de igualdade de género - UBIgual - e do protocolo estabelecido com a CIG para a promoção da Igualdade de Género na Beira Interior.
} 


\section{Revisão de literatura}

\section{Identidade, socialização e performance de género}

Tradicionalmente, "por género entendemos a especificidade de homens e mulheres sob os pontos de vista social, cultural e psicológico» (Schouten 2011, 13). Porém, de acordo com diversas perspetivas teóricas contemporâneas, o conceito de género contém maior sofisticação e dinamismo, o que o torna particularmente difícil de operacionalizar (Pereira 2012). O entendimento sobre os corpos sexuados não se apresenta de forma direta, universal e a-histórica, antes é composto por um combinado de estruturas simbólicas e discursivas que estão na base da naturalização da ideia de sexo "verdadeiro», no sentido de Foucault (1982). Nesta visão, são os discursos predominantes sobre o género que vão dar sentido às diferenças percecionadas nos corpos, uma vez que, como refere Butler, «talvez este constructo ao qual chamamos «sexo» seja tão culturalmente construído quanto o género» (in Pereira 2012, 33). Assim a identidade de género é «uma espécie de (auto)construção, simultaneamente singular e colectiva, onde a participação num determinado género dá forma aos sentimentos e às cognições de cada indivíduo pelo facto de ser homem ou ser mulher» (Ortiz 2010, 17).

A identidade de género é construída desde o nascimento. Vieira (2006) sugere que já no ventre as crianças são tratadas pelas mães de acordo com o seu sexo, muitas vezes reproduzindo estereótipos de género. Todas as pessoas produzem e reproduzem o género nas suas interações sociais (Giddens 2010) porque se representam como sendo seres sexuados, geralmente homens ou mulheres. Grande parte das atividades quotidianas são selecionadas e realizadas em função do que achamos ser indicado para os homens e para as mulheres (Pereira 2012), o que desde sempre tendeu a gerar fortes assimetrias entre atividades e arenas de atuação destes e destas. A temática do género relaciona-se, assim, profundamente com a desigualdade social e com o poder (Sales Oliveira, Vilas Boas, e Las Heras 2016) e foram sobretudo os movimentos feministas do século passado que abriram caminhos à compreensão sobre como se transformam e mantêm as desigualdades e os modelos de género, e como intervir sobre os mesmos.

Refletindo sobre a importância do género na infância, constata-se que as famílias iniciam cedo a edificação do género da criança (Vieira 2006; Cardona et al. 2015; Marchão e Bento 2012). A tendência para a naturalização das diferenças de género encontra-se ainda hoje fortemente difundida no senso comum e mesmo na comunidade científica (Daston 1992; Piscitelli 2009). Geralmente, à mulher associase a falta de aptidão para as ciências exatas, mas uma maior habilidade verbal. Já aos homens é associada maior aptidão para a matemática e para o mundo científico (Amâncio 1993). Estas estereotipias têm marcado de forma relevante a educação, reforçando o encaminhamento de jovens para determinadas áreas vocacionais de acordo com estas ideias que consubstanciam expectativas sociais, por 
um lado, e estereótipos, por outro (Amâncio 1993). Percebe-se que, se é veiculado pelos agentes de socialização que as raparigas devem preferir determinadas áreas e temas e os rapazes outros, os comportamentos destas e destes tenderão a seguir essa norma informal. A influência do que é o feminino e o masculino no processo de socialização através da interpretação biológica das diferenças cognitivas e comportamentais é, assim, uma explicação que reproduz ela própria desigualdades de carácter social e histórico (Sales Oliveira, Vilas Boas, e Las Heras 2016).

Nos últimos anos, e apesar de avanços no combate à desigualdade de género, pode dizer-se que os homens permanecem em papéis sociais mais valorizados e gratificantes e as mulheres tendem, em quase todas as culturas, a ainda deter a responsabilidade primária ligada à educação de menores e do cuidar da casa, mesmo quando conjugada com uma profissão remunerada e responsabilidades sociais ou comunitárias.

De uma maneira geral, a instituição escolar/educativa reproduz essas desigualdades quando socializa as crianças a interpretar como o modelo «certo» $\mathrm{O}$ atual e não promove nas crianças o questionamento dos lugares e papéis desempenhados por homens e mulheres na sociedade atual (Pereira 2012). Esse processo começa desde muito cedo na educação pré-escolar.

\subsection{A educação pré-escolar em Portugal}

Em Portugal a educação pré-escolar desenvolveu-se tardiamente, sendo que só foi alvo de um forte impulsionamento após a revolução de Abril de 1974. Com a democracia, o número de jardins-de-infância e creches aumentou significativamente, bem como o número de escolas de formação de profissionais de educação de infância. Estender a educação pré-escolar a toda a população tornou-se um objetivo nacional que visava promover o bem-estar social e desenvolver as potencialidades das crianças (Decreto-Lei n. ${ }^{\circ}$ 542/79) (ME 1979).

No entanto, esta vontade não correspondeu a uma integração massiva das crianças portuguesas em equipamentos públicos. Apenas tão recentemente como o ano letivo de 2016/17 se concretizou a obrigatoriedade de fornecer uma resposta de educação pré-escolar às crianças que se inscrevam neste nível com quatro ou mais anos de idade (Lei n. ${ }^{\circ}$ 65/2015) (AR 2015). Presentemente, a educação pré-escolar é disponibilizada na rede escolar pública nestas condições. ${ }^{2}$ Fora da rede pública, há a oferta de instituições educativas privadas, onde também pode ser feita a educação pré-escolar. Presentemente, esta oferta dá resposta a cerca de metade da população infantil integrada neste nível escolar, como se pode ver na tabela seguinte.

Sendo que acolhe de acordo com a sua capacidade, dando prioridade às crianças mais velhas, ou seja, mais próximas da idade de ingresso na escolaridade obrigatória. 
Tabela 1.

Alunos e alunas matriculado/das na educação pré-escolar: total e por subsistema de ensino

\begin{tabular}{|cccc}
\hline & \multicolumn{3}{c}{ Subsistema de ensino } \\
\hline Anos & Total & Público & Privado \\
\hline $\mathbf{1 9 6 1}$ & 6.528 & $/ /$ & 6.528 \\
$\mathbf{1 9 7 0}$ & 15.153 & $/ /$ & 15.153 \\
$\mathbf{1 9 8 0}$ & 80.373 & $\mathrm{x}$ & $\mathrm{x}$ \\
$\mathbf{1 9 9 0}$ & 161.629 & 70.730 & 90.899 \\
$\mathbf{1 9 9 5}$ & 185.088 & 81.952 & 103.136 \\
$\mathbf{2 0 0 0}$ & 228.459 & 113.644 & 114.815 \\
$\mathbf{2 0 0 5}$ & 259.788 & 137.297 & 122.491 \\
$\mathbf{2 0 1 0}$ & 274.387 & 141.044 & 133.343 \\
$\mathbf{2 0 1 5}$ & 264.660 & 141.571 & 123.089 \\
$\mathbf{2 0 1 6}$ & 259.850 & 137.573 & 122.277 \\
\hline
\end{tabular}

Fontes de Dados: DGEEC/MEd - MCTES - Recenseamento Escolar Fonte: PORDATA

Última actualização: 2017-07-03

Na sequência da criação das Orientações Curriculares para a Educação Pré-escolar - OCEPE (ME 1997), a educação pré-escolar passou a ser assumida como uma etapa fundamental, valorizando a promoção da autoestima, da confiança e da capacidade reflexiva das crianças, para que cada uma identifique quais as suas próprias possibilidades e progressos. A recente revisão destas orientações (I. L. Silva et al. 2016) acentuou os aspetos de formação pessoal e social onde se insere a educação para a igualdade de oportunidades, destacando-se em particular a igualdade de género.

Caracterizando agora o grupo profissional de educadores e educadoras de infância a exercer na Educação Pré-escolar, é importante começar por salientar que a sua taxa de feminização é de 99,1\% (Ribeiro 2015), o que, no nosso entender, deve ser interpretado à luz das representações sobre a sua profissionalidade: os cuidados e a educação de crianças pequenas têm sido áreas profissionais socialmente construídas como femininas (Pires 2007).

Nos anos 1970, foram criadas as Escolas Superiores de Educação e promovidos cursos de formação profissional nesta área, procurando corresponder ao alargamento que se pretendia fazer da educação pré-escolar. Contudo, até praticamente ao final do século passado, a educação de infância em Portugal debateu-se com problemas variados relacionados com a falta de verbas - que claramente traduziam uma aposta insuficiente neste nível - bem como com o baixo estatuto de educadoras e educadores (Infante 2008). Assim, apesar das políticas públicas recentes indiciarem uma aposta mais firme neste nível educacional, a um nível social alargado, não é ainda consensual a sua importância, permanecendo a sua 
relativa desvalorização em relação à educação primária (Cardona 2008; Infante 2008). Esta situação reflete-se na cultura e nos contextos profissionais e é potencialmente geradora de insatisfação e tensão (num cenário em que cada vez mais os e as profissionais da Educação Pré-escolar têm condições e conteúdos de trabalho mais exigentes - grupos maiores, tarefas administrativas adicionais).

Algumas autoras sugerem que permanece na prática profissional da educação de infância uma excessiva informalidade que dificulta não só a sua definição (Cardona 2008), como tende a conduzir a uma desvalorização dos seus saberes e competências por este grupo profissional, que não reflete criticamente sobre as suas práticas por não se sentir apto no papel de produtor de conhecimento (Coelho 2004). Há, no entanto, outras visões, que consideram que a profissão se tem enriquecido muito nos últimos anos, à medida que as áreas científicas que estão na sua base têm vindo a desenvolver corpos teóricos cada vez mais sólidos (Pires 2007). Parece-nos que provavelmente ambas as visões são válidas e não se excluem mutuamente, fazendo com que, apesar de estar em curso um processo de valorização da profissão, esta possa ainda oferecer aos e às profissionais, em determinadas circunstâncias e contextos, dificuldades de legitimação das suas práticas.

É, portanto, num cenário de complexidade e alguma contradição dos contextos de exercício profissional que temos que situar a presente investigação.

\section{Cidadania e igualdade no jardim-de-infância}

A pedagogia igualitária deve iniciar-se nas idades mais prematuras para que as crianças aprendam a posicionar-se perante o mundo e os outros de acordo com os princípios da cidadania e igualdade de oportunidades (Vasconcelos 2007). De uma maneira geral, as crianças de hoje começam bastante cedo a ter contacto com outras pessoas fora do seio familiar, entre as quais os grupos de pares, o que traz à sua aprendizagem dos papéis sociais de género uma maior diversidade de agentes. No entanto, nem sempre a importância destes «novos» agentes é devidamente considerada. É frequente a invisibilidade do grupo de pares como um importante contexto de aprendizagem (Coelho 2004).

A educação pré-escolar ${ }^{3}$ enquanto instituição educativa tem um papel central na aprendizagem de competências sociais, cabendo-lhe oferecer e proporcionar a responsabilidade pessoal e comunitária (Cardona et al. 2015). No jardim-de-infância, as crianças experienciam quotidianamente situações de partilha de poder - espaço, brinquedos, conflitos entre pares - e estes contactos, a par das experiências familiares, vão ter influência decisiva na sua ação futura. Nestas interações, as questões de igualdade/assimetria de género estão muitas vezes subjacentes e

Aqui no seu sentido mais amplo, que abrange as crianças desde o nascimento até à entrada na escolaridade obrigatória e que, segundo Cardona (2008), engloba as dimensões do educar e do cuidar. 
as educadoras assumem um papel fulcral visto que podem, através do debate e da desconstrução, desenvolver uma ação pedagógica igualitária gerando um ambiente propício para a criança construir a sua identidade de género e a sua relação com os seus pares sem o fazer de forma estereotipada (Marchão e Bento 2012; Prates e Marchão 2015).

Atualmente existe uma preocupação assumida com a pedagogia igualitária ao nível de direitos e de oportunidades, ou seja, o desenvolvimento de uma «escola inclusiva», em que a diversidade deve ser valorizada. Ao nível da Educação Pré-escolar, essa preocupação está vertida nas atuais OCEPE (I. L. Silva et al. 2016). Contudo, para haver uma efetiva pedagogia para a igualdade, tem de se legitimar e incorporar a igualdade ao nível organizacional e essa nem sempre é a realidade das instituições educativas em Portugal, nomeadamente as IPSS (Monteiro e Sales Oliveira 2014).

Por outro lado, a educação de infância foca-se muito no corpo da criança e sofre a influência do contexto cultural em que vive (Vianna e Finco 2009). Homens e mulheres educam as crianças demarcando nos seus corpos diferenças de género, sendo que as características físicas e os comportamentos socialmente esperados segundo o género são reforçados nos gestos e nas práticas do dia-a-dia, muitas vezes de forma inconsciente. Grande parte do que é valorizado para a menina não é apreciado para o menino e vice-versa. O processo de construção da feminilidade e da masculinidade dos corpos e dos sentimentos relaciona-se com as expectativas sociais presentes na nossa cultura. Por tudo isto, é crucial que educadoras, educadores e auxiliares adeqúem as atividades para estimular na criança competências várias e um sentido de justiça. As atividades lúdicas e pedagógicas devem promover a redução de estereótipos de género. A brincadeira é dos momentos mais importantes da infância, pois é nesta que as crianças recriam situações em que desempenham papéis como ser mãe, pai, mulher e homem. Inconscientemente, muitas vezes as crianças reproduzem práticas sexistas que estão interiorizadas no próprio seio familiar. É aqui que a Educação Pré-escolar deve colaborar para o desenvolvimento de valores não discriminatórios nas crianças (Gomes 2012).

Ao ter subjacente uma visão muitas vezes romântica e idílica da infância, a Educação Pré-escolar em Portugal tende a não só reforçar inadvertidamente as diferenças sociais - privilegiando um modelo expressivo - como também a ser algo acrítica e pouco reflexiva relativamente às influências do meio sociocultural de origem das crianças e aos saberes que estas trazem com elas (Cardona 2008). Adicionalmente, grande parte das práticas pedagógicas que ocorrem contêm potencialmente discriminação, pois derivam de ideias e práticas estereotipadas do pai, da mãe, da educadora, da auxiliar educativa sobre os diferentes papéis de género, visto que também eles e elas passaram por uma socialização com práticas diferentes segundo o género (Vieira 2013).

O trabalho de sensibilização de educadoras e educadores para a igualdade de género e uma educação igualitária é assim muito importante. Porém, mais importante ainda será inserir mudanças estruturais para o cumprimento efetivo de uma 
cidadania paritária (I. L. Silva et al. 2016). Neste contexto a formação contínua de docentes é estratégica para o desenvolvimento de uma educação mais igualitária, estimulando à inovação pedagógica. O projeto «Coeducação» (1998-2001), por exemplo, promoveu e desenvolveu materiais pedagógicos para a formação inicial de docentes. Mais recentemente - 2010 - os guiões desenvolvidos pela Comissão para a Cidadania e Igualdade de Género (CIG), bem como as oficinas de formação baseadas nestes, têm procurado fomentar uma sensibilização e formação dos profissionais da docência, em que se inclui a Educação Pré-escolar (CIG 2014). Porém, a este respeito, Coelho (2004) alertou para o facto de que a frequência de cursos de formação na área da igualdade de género nem sempre consegue modificar substancialmente os sistemas de crenças das e dos profissionais de educação. Uma dimensão a explorar será a análise de performances de género de profissionais e auxiliares de educação, visto que a aparência, as identidades e os estilos pedagógicos são também moldados por normas de género (Pereira 2012).

\section{Pesquisa empírica: opções metodológicas}

A instituição em que se efetuou o estudo é uma instituição central e de referência na cidade em que se situa. Trata-se de uma IPSS de cariz religioso localizada numa cidade média da Beira Interior, em Portugal. A presença na instituição decorreu de novembro de 2015 a julho de 2016. No ano anterior à pesquisa (2014/15), duas educadoras de infância e uma educadora social foram formandas da instituição numa oficina de formação sobre Educação, Género e Cidadania. A sala onde se efetuou a pesquisa tinha nesse ano letivo um grupo de dezasseis crianças, oito meninas e oito meninos, com idades entre os quatro e os seis anos, acompanhadas por uma educadora e uma auxiliar de ação educativa, que é freira.

A estratégia metodológica desta investigação foi de cariz qualitativo, visto que se pretendia compreender contextos de interação, relações e práticas. Relembramos os objetivos gerais desta investigação: observar como se realiza o processo de socialização de género entre as crianças; perceber qual a atitude da instituição e da educadora em relação ao género e à socialização de género; analisar as práticas educativas quotidianas da equipa educativa numa perspetiva de género. Considerou-se que seria adequada uma abordagem de tipo etnográfico com presença prolongada no terreno, procurando «encontrar significados através das narrativas verbais e de observações em vez de números» (Bento 2012, 1). A etnografia é particularmente vantajosa para se abordar o «banal» e o familiar, permitindo refletir sobre o que já se pensava conhecer, tendo para tal o etnógrafo ou etnógrafa de viver dentro do contexto que investiga (Fino 2011).

Sendo uma investigação de cariz exploratório, optou-se por um modelo de análise flexível, assente sobretudo nos objetivos delineados, que permitiram ainda assim elencar dimensões principais de análise com base na revisão de literatura, 
mas deixando espaço em aberto para novos indicadores ou novas dimensões de análise que pudessem surgir no decorrer da pesquisa. Apresentando o modelo de análise de forma sumária, este caracterizou-se por ter como conceito central a socialização de género, da qual emergem cinco dimensões, uma institucional, duas relacionadas com a equipa educativa e outras duas com as crianças. Ao nível da instituição, interessou-nos compreender os valores desta e a sua cultura bem como as rotinas da instituição, numa vertente mais imaterial da instituição. Esta dimensão e seus indicadores foram estabelecidos já durante a observação, tendo esta evidenciado a sua pertinência. Paralelamente, analisaram-se os espaços e os materiais. Em relação às educadoras, analisaram-se as práticas educativas e pedagógicas e também as suas representações; junto das crianças, definiram-se como focos de análise as suas interações (com a equipa educativa e com o grupo de pares) e as suas escolhas ou manifestações individuais.

Optou-se pela observação direta não participante porque a investigadora responsável pelo trabalho de campo não possuía habilitações adequadas para integrar a equipa educativa. Revelou-se fundamental ter um período de observação longo, para dar tempo à aceitação da presença da investigadora e à sua consequente neutralização (Denzin e Lincoln 2003).

Ao longo da investigação no terreno, utilizou-se um diário de campo para registar as observações. Recorreu-se ainda ao registo fotográfico de materiais brinquedos, espaços e trabalhos - como facilitador da análise posterior. Levou-se a cabo uma análise de conteúdo do projecto educativo da sala em observação e do regulamento geral da instituição com o objetivo de compreender as linhas orientadoras da instituição e da sala, e foi efetuada uma entrevista semiestruturada à educadora responsável pela sala que se observou. O objetivo de acionar esta técnica de recolha de dados complementar foi compreender a visão e a perspetiva desta profissional sobre a sua sala e as suas práticas, trazendo informação adicional que pudesse ser confrontada com as observações e a análise documental. O uso de três fontes - dados recolhidos na observação, dados da entrevista e documentos analisados - possibilitou uma complementaridade e confronto das informações recolhidas, o que nesta investigação era particularmente importante, visto que se pretendia obter a máxima profundidade no entendimento das práticas e dos contextos educativos.

\section{Apresentação e discussão de resultados}

\section{O que salta à vista: cores e brinquedos}

Na sala observada, foi desde logo evidente uma distinção de género nas cores e materiais. Na instituição em estudo é obrigatório o uso de bibe para as crianças e verificámos que os mesmos são diferenciados para meninos e meninas: bibes pretos 
ou azuis para meninos e vermelhos ou cor-de-rosa para meninas. Importa referir que os bibes são adquiridos pela família, sem qualquer condicionalismo de cor, mas obrigatoriamente na instituição, que apresenta exclusivamente a oferta das cores referidas. Todos os meninos da sala (oito casos) apresentavam bibes de duas cores, preto ou azul, cores que tradicionalmente são mais associadas ao sexo masculino. Observou-se alguma personalização dos bibes: dois meninos tinham bibes com desenhos; um menino tinha no seu bibe um carro e outro menino, o homem-aranha. Nas meninas, observou-se também a exclusividade de duas cores; três meninas tinham bibe vermelho claro e as restantes (cinco casos) meninas usavam bibes cor-de-rosa. Uma menina apresentava no seu bibe o desenho da Hello Kitty e outra menina tinha o desenho da Minnie. Verificaram-se assim diferenças ligadas ao género na indumentária escolar, com diferentes cores para meninos e meninas e homogeneidade dentro de cada grupo do mesmo sexo. A educadora e a auxiliar também usavam bibes da instituição, mas com uma maior diversidade na escolha da cor, tendo a educadora um bibe azul.

Passando agora aos brinquedos, na tabela seguinte apresentamos uma lista dos brinquedos disponíveis.

Tabela 2.

Brinquedos existentes na sala

\begin{tabular}{|l|}
\hline Camas e roupas de cama de bebé \\
\hline Carros de bebés \\
\hline Loiça e talheres de brincar \\
\hline Lancheiras \\
\hline Roupa de cama de bebé \\
\hline Vestuário de bebés \\
\hline Telefones cor-de-rosa \\
\hline Carros (jipes, carrinhas, etc.) \\
\hline Bonecos (de banda desenhada e filmes de animação \\
\hline Animais de brincar \\
\hline Brinquedos de madeira \\
\hline Legos \\
\hline Puzzles \\
\hline Jogos temáticos \\
\hline
\end{tabular}

Pode observar-se que a maioria dos brinquedos existentes reproduz aquilo que é tradicionalmente direcionado para meninos (por exemplo carros) e para meninas (materiais domésticos e de bebés). Os brinquedos do fim da lista, que são os aparentemente mais neutros em termos de género, acabam por expressar também esta reprodução de estereótipos visto que, quer os puzzles, quer os legos 
apresentam padrões e temas estereotipados (por exemplo, princesas, construções, etc.). Quanto à arrumação dos brinquedos, o espaço com maior visibilidade é a área do «tapete» onde se encontra a «casinha» como se pode ver na figura 1, onde estão guardados os brinquedos referentes a essa área de brincadeira.

\section{Figura 1.}

Casinha

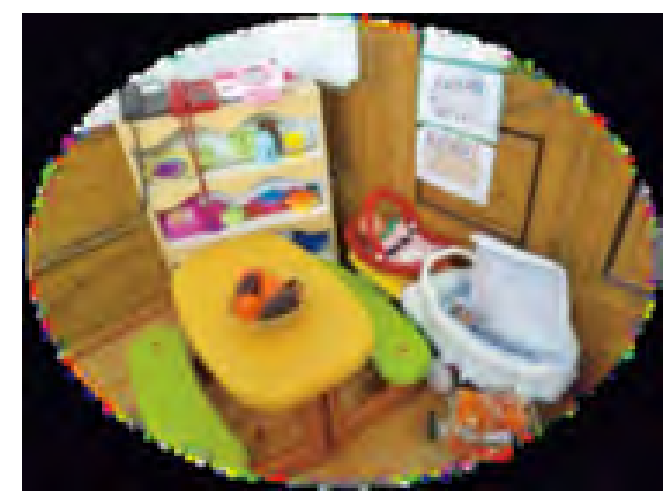

(C)Autoras

Os carros e legos encontram-se guardados em caixas e em baldes grandes existentes na sala, como se pode verificar na figura seguinte.

Figura 2.

Balde de arrumação

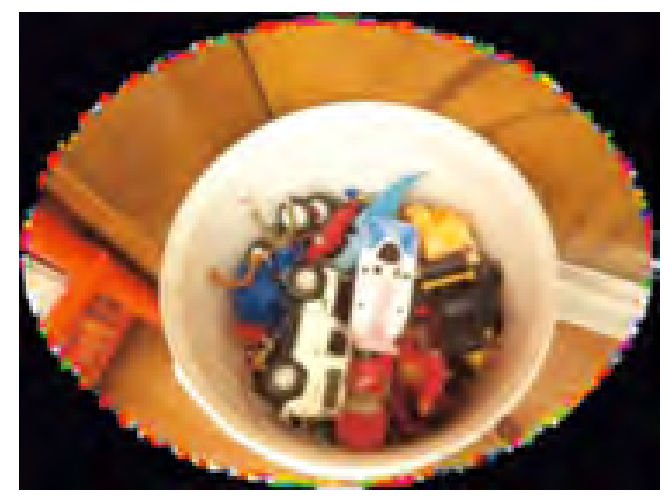

(C)Autoras

Há, no entanto, fatores que se devem ter aqui em conta, dos quais se tomou conhecimento durante o período de observação: os brinquedos da sala (bem como do resto da instituição) são, sobretudo, brinquedos que foram doados e que vão permanecendo nas salas de uns anos para os outros. É difícil, por questões finan- 
ceiras, adquirir brinquedos mais igualitários quanto ao género, que já existem no mercado. Por outro lado, a existência de brinquedos estereotipados não é condição sine qua non para que o seu uso o seja, defendendo algumas autoras e autores que as crianças devem ter livre acesso a todo o tipo de brinquedos e não encarar estes, à partida, como segmentados pelo sexo (Vieira 2013). Assim, o que importa é sobretudo a atitude dos adultos e das crianças face a estes - que vamos abordar no ponto seguinte - e que deverá ser baseado na liberdade e no incentivo da diversidade (Vieira 2013).

\section{O que se faz: brincadeiras, desenhos e atividades}

\section{As brincadeiras}

Ao longo dos oito meses de trabalho de campo, tivemos o privilégio de observar imensas brincadeiras deste grupo de meninas e meninos. Verificou-se uma forte tendência das crianças para o agrupamento de acordo com o sexo, sendo a larga maioria das brincadeiras observadas entre grupos do mesmo sexo. Os meninos brincam juntos, sobretudo nas seguintes brincadeiras: legos (observado 14 vezes), carros (30 observações), bonecos alusivos a banda desenhada ou cinema (23 observações), objetos de madeira (8 observações), construções (12 observações), jogos de pistolas (10 observações), futebol e basquetebol (14 observações), com bolas pequenas (16 observações) e com o tablet (observado 21 vezes), que é trazido de casa, não sendo fornecido pela instituição. Observaram-se meninos a brincar na «zona da casinha», utilizando legos e com o tablet (12 observações), ou seja, reaproveitando a zona, sobretudo a mesa, para outro uso.

Nas brincadeiras das meninas, evidenciaram-se os jogos do cuidar (bebés, roupas, carros de bebé, cama e tudo o que envolve brincar à maternidade) (observado 31 vezes). São mais as meninas que se dedicam à construção de puzzles (16 observações) e jogos temáticos, relacionados, por exemplo, com a casa e animais de companhia (9). Outras brincadeiras frequentes são com bonecas (13 observações), o «fazer de conta que nos maquilhamos» (18 observações), «fazer de conta que tiramos fotografias» (7 observações), «às cabeleireiras» com o uso de objetos diversificados (19 observações), brincar na «casinha» (tachos, pratos, «fazer comida», «mãe e filha») (observado 24 vezes), com objetos de madeira (6 observações) e cantarem as músicas que passam no rádio na sala de ATL (16) ${ }^{4}$ e brincar «ao acampamento» ${ }^{5}$ ( 5 observações).

Quanto às brincadeiras mistas, ou seja, em que meninos e meninas brincaram juntos, observaram-se com alguma regularidade: «ao casamento» (jogo simbólico em que o menino era o homem-noivo e a menina a mulher-noiva) (8 observações); com puzzles (5 vezes); com carros (mas sempre com maioria de participantes

\footnotetext{
Ligado com frequência e sintonizado para estações generalistas.

Jogo simbólico com a atividade de tempos livres - acampar.
} 
do sexo masculino, por exemplo, 5 meninos e 1 menina a brincar com os carros) (4 observações); com os objetos de madeira, com cartas (8 observações), discos voadores dos Angry Birds (7 observações), legos (6 observações), «ao comboio» (4 observações), à «luta com bonecos» (7 observações).

$\mathrm{Na}$ área da casinha, raramente há rapazes (apenas 4 observações). Nesta sala, as meninas estão mais presentes e têm preferência por brincar com os brinquedos que as transportam para a maternidade, como o «brincar à mãe e filha», destacando-se algumas frases ouvidas: «Estou a tomar conta do meu filho», ${ }^{6}$ "Mãe, recebeste uma mensagem $»,{ }^{7}$ e brincar com os bebés, tapando-os nas suas camas ou vestindo e despindo o bebé, dando comida ao bebé. Também demonstram apetência pelos brinquedos que as levam para o mundo doméstico, como os tachos, os copos, as lancheiras, talheres, entre outros, e brincam a algumas profissões geralmente referenciadas ao sexo feminino, como é o caso de brincarem «às cabeleireiras», destacando-se algumas frases que algumas meninas diziam enquanto brincavam: «Vamos esticar o cabelo»; «Vou pôr aqui um produto, tsssss»; «Vou pôr um produto para o cabelo ficar mais bonito». ${ }^{8}$

Os meninos manifestam grande interesse nos legos, nos carros e nas construções (ver figura seguinte) e brincam sempre juntos neste tipo de brincadeiras. «Isto é o parque de estacionamento» e «Eu quero um [carro] vermelho»; «É um Toyota, olha o meu carro! ${ }^{10} \mathrm{e}$ «O meu pai tem Supermúsculos». ${ }^{11}$

\section{Figura 3.}

Estrada construída por meninos

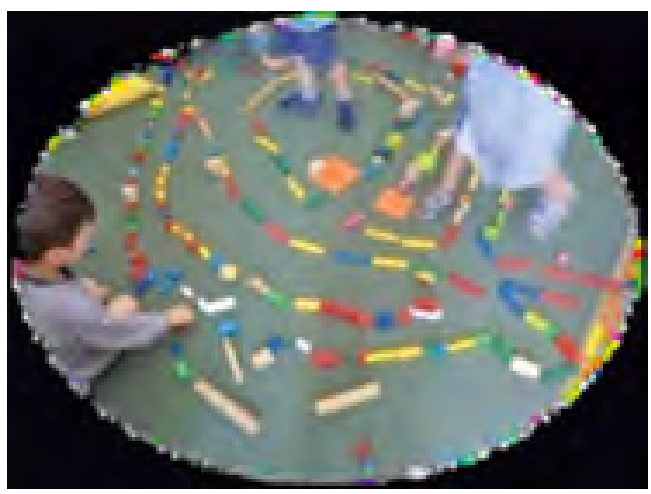

(C)Autoras

Diário de campo, frase pronunciada por menina de 5 anos, janeiro de 2016. Diário de campo, frase pronunciada por menina de 6 anos, fevereiro de 2016. Diário de campo, frases pronunciadas por menina de 5 anos, maio de 2016. Diário de campo, frase pronunciada por menino 6 anos, janeiro de 2016. Diário de campo, frase pronunciadas por menino de 5 anos, janeiro de 2016. Diário de campo, frase pronunciada por menino de 5 anos, janeiro de 2016. 
A análise destas brincadeiras remete-nos para a interpretação de alguns autores e autoras sobre a procura por parte das crianças de pessoas «iguais a elas».

Para explicar a segregação dos sexos observada na infância, Carole Beal (1994) apresenta duas ordens de razões. Em primeiro lugar, afirma que as crianças preferem brincar com outras do mesmo sexo em virtude de semelhança mútua, ao nível dos estilos de interação. Em segundo lugar, fala da necessidade individual de desenvolvimento da identidade de género que conduz as crianças a procurar contactar, preferencialmente, com outras parecidas consigo, isto é, outras que correspondam aos modelos apreendidos do que «é ser rapaz» ou «ser rapariga». (Cardona et al. 2015, 21)

Estas preferências dão base ao desenvolvimento da identidade de género da criança, consolidando a interiorização dos papéis de género que são percecionados como adequados: rapazes e raparigas tendem a manifestar preferência pelos brinquedos associados ao seu sexo. Esta tendência distinta contribui para a formação dos esquemas de género (Bem 1981, citado por Vieira 2013), os quais, por constituírem uma rede de informações cognitivamente associadas ao género, «reforçam a preferência da criança por atividades e papéis típicos do seu sexo, levando-a a evitar a exibição de interesses e comportamentos entendidos como típicos do sexo oposto» (Vieira 2013,27). Importa referir que na sala não há nenhuma planificação semanal ou mensal dos espaços, brincando as crianças livremente.

Já ao nível dos desenhos, pinturas e trabalhos manuais, constatou-se um misto de solicitação espontânea das crianças para efetuar este tipo de atividades (sobretudo desenhos e pinturas e sobretudo das meninas) com a realização de trabalhos temáticos por indicação da educadora. Nestes, destacaram-se fortemente os motivos tradicionais, como, por exemplo, uma gravata para o dia do pai e uma flor para o dia da mãe. Todas as crianças realizaram todos os trabalhos. A liberdade de escolha de cada criança manifestou-se na seleção das cores, que, no caso das pinturas, era mais limitada devido à existência de poucas cores disponíveis. Observando a escolha de meninos, as cores que mais escolhem por ordem de frequência são: azul (3 escolhas), amarelo e verde (2 escolhas), roxo (1 escolha), rosa (1 escolha), castanho e preto (1 escolha). No caso da seleção das meninas, em primeiro lugar está o verde (4 escolhas), o laranja e o amarelo (2 escolha), seguindo-se as cores com menos eleição: azul (1 escolha), vermelho e castanho (1 escolha). Observou-se também uma associação das cores aos trabalhos, por exemplo, no caso da gravata para o pai, as cores rosa e laranja não foram usadas nem por meninos nem por meninas mas, no caso da prenda do dia da mãe, essas cores foram usadas por crianças dos dois sexos. 


\section{O que se diz e como se diz}

De uma maneira geral as repreensões por nós observadas, dadas aos meninos e às meninas, não recorrem a estereótipos de género. Contudo, algumas frases são exemplos ilustrativos interessantes, por exemplo, «Vais para alguma festa hoje?» «Olha os sapatos da Carla», «Nós adultas, não percebemos nada disto, ela é que anda sempre na moda, nós não sabemos», ${ }^{12}$ são frases ditas pela educadora a meninas, o que no nosso entender corporiza uma imagem feminizada da mulher, ou seja, a ideia tradicional do que a mulher deve ser, de como se deve vestir segundo o seu sexo. Já em relação à auxiliar da sala, foi muito explícita a presença de estereótipos de género no seu discurso. Por exemplo, de que o cor-de-rosa é das meninas: «Para ti, tem de ser rosa, não é?», de a imagem da mulher ser dócil, frágil e de que o seu papel de género deve ser relacionado com a vida doméstica, «Mas tens de lavar senão não és uma boa dona de casa», concomitante com o fomento do imaginário de conto de fadas, "Com aqueles sapatos, parece uma Cinderela». O reforço da ideia de que elas são frágeis: «Não há aqui choros, só as raparigas é que andam sempre nisto», «Isto é coisa de mulher, não é?» ${ }^{13}$

\section{Como nos vemos e (d)escrevemos}

Entrevistou-se a educadora da sala em observação. Pretendia-se confrontar as perceções e representações desta profissional com a observação da sala. Ao mesmo tempo, visava-se dar voz à agente educativa não apenas enquanto elemento importante nas interações observadas mas também como protagonista do processo formativo que efetuou. Assim, na entrevista, focou-se não apenas a dinâmica da sala e a questão do género, mas também a ligação à oficina de formação frequentada e o uso dos guiões da CIG.

O que motivou esta educadora a participar na formação «foi a curiosidade, o interesse e perceber como se deve lidar com algumas situações que surgem». Relativamente à aplicação quotidiana das aprendizagens, a educadora de infância considera que

no dia-a-dia não [consegue aplicar] porque há coisas demasiado enraizadas que inconscientemente a gente ainda faz sem se aperceber [...] mas geralmente quando estamos a tratar determinados assuntos tento que as coisas sejam equilibradas para ambos os sexos e que não haja discriminação. (Educadora, mulher, 52 anos)

Refere ainda que quando trabalha determinados temas tenta evitar estereótipos de género. No seu projeto educativo deste ano, procurou inserir o tema visto

12 Diário de campo, educadora, janeiro de 2016.

13 Diário de campo, auxiliar de ação educativa, junho de 2016. 
que «é um tema muito vasto que se pode tratar de quinhentas maneiras e, pronto, tentei trabalhar com as crianças um modo diferente do que se tinha feito até aqui, tentando igualar as situações que foram aparecendo».

Quanto à forma como a profissional vê a sua sala após a formação efetuada, refere que

é óbvio que tem de se ver as coisas de maneira diferente. [...] eu noto que as crianças ainda trazem enraizado a diferenciação quer em brincadeiras, quer em atividades, quer no manuseamento de materiais, e ainda acham que as meninas fazem determinadas coisas e os meninos fazem outras coisas e não podemos de maneira nenhuma impor, mas fazer ver e explicar que só assim é que eles percebem porque é que todos usufruímos de tudo o que está ao dispor independentemente do sexo ou não. (educadora, mulher, 52 anos)

Relativamente às condições proporcionadas pela instituição, a educadora considera que, «apesar de estarmos numa instituição religiosa, temos perfeita autonomia para explorarmos o que quisermos. [...] este tema de igualdade de género não vai de maneira nenhuma contra aquilo que se pratica».

A análise documental do projeto educativo da sala para o corrente ano e do regulamento da instituição evidenciou a presença de preocupações com a cidadania e a justiça social, enquadradas na cultura da instituição, que, como se referiu, é de cariz religioso. Não há referência explícita às questões de género. Os conceitos de educação e os valores desta instituição são fortemente influenciados pela religião e pelos ensinamentos da irmã fundadora da instituição, que representa uma referência na sua cultura organizacional. Esta presença simbólica feminina vem reforçar a forte feminização da equipa de trabalho da instituição, onde apenas trabalham mulheres, o que é muito frequente em IPSS (Monteiro e Sales Oliveira 2014).

\section{Considerações finais}

Perante os questionamentos e inquietações que o statu quo nos levantava, procurámos averiguar no contexto de uma sala de educação pré-escolar em que medida e com que contornos a socialização e a performatividade de género na educação pré-escolar reproduzem ou contrariam estereótipos. Tirando partido das oficinas de formação levadas a cabo no ano letivo anterior ao estudo, procurou-se perceber se a profissional que trabalha neste nível educativo, e frequentou a formação especificamente orientada para a intervenção em igualdade de género, promove quotidianamente este valor nas suas práticas educativas.

Em consonância com o referido na literatura (Coelho 2004), evidenciou-se a relevância da relação interpares das crianças e a sua importância na construção de 
uma identidade de género que, no entanto, na sala observada, se pauta por ser de acordo com os modelos tradicionais de feminilidade e de masculinidade. Ficou por isso patente, sobretudo na observação etnográfica das brincadeiras das crianças, a existência de um espaço carente de intervenção, o que, na nossa opinião, sublinha o papel determinante que as instituições educativas e as educadoras e educadores podem desempenhar, conforme sugerido por Marchão e Bento (2012). De um ponto de vista teórico-conceptual, esta relevância sublinha a pertinência e o potencial de uma abordagem de performatividade de género (Pereira 2012), à qual procurámos dar algum espaço nesta investigação, tendo-nos baseado, contudo, mais na abordagem mais clássica da socialização de género.

Por outro lado, o trabalho de campo também permitiu ilustrar as dificuldades com que educadoras e educadores se defrontam não só pela complexa articulação com o contexto cultural e familiar das crianças (Sarmento 2016) como também pelas suas próprias condições e representações profissionais (Coelho 2004). A este respeito, na instituição estudada, a especificidade da sua cultura institucional, fortemente marcada pela doutrina religiosa, é um aspeto adicional a ter em conta para arquitetar qualquer plano de mudança, visto que (embora na opinião da educadora entrevistada o cariz religioso da instituição não tenha representado uma barreira à introdução da temática da igualdade de género) será importante aprofundar como se estabelecerá a interação entre aquilo que são os valores da igualdade de género, por um lado, e a moral religiosa católica, por outro, nomeadamente no que concerne ao papel social da mulher.

O interesse pela temática da igualdade de género é relativamente recente nesta instituição e foi desencadeado pelas apetências profissionais e pessoais das educadoras que frequentaram a oficina. Afigura-se-nos importante esta abertura da instituição e das pessoas que nela trabalham à temática, não obstante a mesma não se constituir como um valor estruturante do projeto educativo. O papel das educadoras que frequentaram a oficina de formação em género, educação e cidadania, ilustrado na voz da educadora entrevistada, apresenta potencial para ser catalisador da mudança institucional. No entanto, esta constatação tem somente o cariz de indício, visto que, para poder aferir efetivamente este potencial, será necessário auscultar toda a equipa educativa, bem como a direção da instituição.

Por outro lado, e tal como foi assumido pela educadora entrevistada e ficou patente na observação, tendem a permanecer traços de um sistema de crenças estereotipado e, tal como está referido na literatura (Coelho 2004), é incontornável a necessidade de um trabalho de aprofundamento e reflexão sobre as práticas e dinâmicas educativas, trabalho esse que não é compatível com a agenda atual de trabalho desta profissional.

Assim, evidenciaram-se alguns obstáculos que se levantam à implementação de práticas pedagógicas igualitárias: uma certa rotinização de procedimentos como tónica dominante no plano de atividades da sala, com a predominância 
de atividades «confortáveis», porque recorrentes e socialmente consensuais. É o exemplo da celebração dos Dias do Pai ou da Mãe em que impera uma visão tradicional da representação destas relações familiares e onde a própria margem para a expressão livre das crianças é diminuta. Neste sentido, alguns dos alertas mencionados nos nossos resultados afiguram-se-nos especialmente pertinentes como indicadores para a reflexão. Podemos dar como sugestões concretas um aumentar do diálogo e problematização com as crianças em redor de determinadas escolhas, a atualização dos materiais evitando os que são promotores de estereótipos e favorecendo os promotores de uma pedagogia igualitária, uma maior diversidade nas atividades estruturadas e um uso mais alargado dos recursos disponíveis para a promoção da igualdade de género nestas faixas etárias, nomeadamente os guiões da CIG.

Por fim, e apesar destas sugestões, consideramos essencial frisar que, tal como referido por Ana Silva (2005), a real incorporação de uma pedagogia igualitária carece de uma mudança estrutural, dificilmente podendo ocorrer de forma isolada numa sala ou mesmo numa instituição. Neste sentido, a revisão das OCEPE (I. L. Silva et al. 2016) surge como um bom prenúncio e será interessante analisar num futuro próximo se gerou alterações nesta sala e na instituição.

Esperamos com esta investigação ter contribuído para a construção do conhecimento sobre o estado atual da educação pré-escolar e dos desafios e obstáculos que se colocam à mesma para a prossecução dos objetivos de uma pedagogia igualitária de género.

\section{Referências bibliográficas}

Alvarez, Teresa, e Cristina Vieira. 2014. «O papel da educação no caminho que falta percorrer em Portugal na desconstrução dos estereótipos de género: breves reflexões». Exedra - Suplemento Sexualidade, Género e Educação 8-17. Disponível em http://www. exedrajournal.com/?p=323\#

Amâncio, Lígia. 1993. «Género: representações e identidades. Análise das representações do masculino e do feminino e sua articulação com as identidades». Sociologia: problemas e práticas 14: 127-140. Disponível em http://sociologiapp.iscte-iul.pt/pdfs/26/261.pdf

AR - Assembleia da República. 2015. «Lei n. ${ }^{\circ}$ 65/2015, de 3 de julho: Primeira alteração à Lei n. ${ }^{\circ} 85 / 2009$, de 27 de agosto, estabelecendo a universalidade da educação pré-escolar para as crianças a partir dos 4 anos de idade», Diário da República, 128, 1. ${ }^{a}$ Série: 4572. Disponível em https://dre.pt/application/file/67649249

Bento, António. 2012. «Investigação quantitativa e qualitativa: Dicotomia ou complementaridade?» Revista JA 64(1): 40-43.

Cardona, Maria João. 2008. «Para uma pedagogia da educação pré-escolar: fundamentos e conceitos». Revista da Investigação às Práticas. Estudos de natureza educacional 8(1): 13-35.

Cardona, Maria José (coord.), Conceição Nogueira, Cristina Vieira, Marta Uva, e Teresa-Cláudia Tavares. 2015. Guião de Educação Género e Cidadania. Pré-Escolar. Lisboa: Comissão para a Cidadania e Igualdade de Género (CIG). Disponível em https:// www.cig.gov.pt/wp-content/uploads/2015/10/398_15_Guiao_Pre_escolar.pdf 
CIG - Comissão para a Cidadania e Igualdade de Género. 2014. Notícias 90. Disponível em https://www.cig.gov.pt/2014/10/noticias-90-coeducacao-percursos-e-desafios

Coelho, Ana Maria. 2004. Educação e cuidados em creche: conceptualizações de um grupo de educadoras. Tese de doutoramento, Universidade de Aveiro.

Daston, Loraine. 1992. «The naturalized female intellect». Science in context 5(2): 209-235. DOI: https://doi.org/10.1017/S0269889700001162

Denzin, Norman, e Yvonna Lincoln. 2003. The Sage Handbook of Qualitative Research. Thousand Oaks, CA: Sage.

Giddens, Anthony. 2010. Sociologia. Lisboa: Fundação Calouste Gulbenkian.

Gomes, Vânia. 2012. A promoção da igualdade de género com recurso à atividade lúdica - uma experiência com crianças de educação pré-escolar. Dissertação de mestrado, Instituto Politécnico de Castelo Branco.

Fino, Carlos N. 2011. «Inovação Pedagógica, Etnografia, Distanciação». In Etnografia da Educação, ed. Carlos N. Fino, 99-118. Funchal: Universidade da Madeira - CIE-Uma.

Foucault, Michel. 1982. Herculine Barbin: O diário de uma hermafrodita. Rio de Janeiro: F. Alves.

Infante, Maria José. 2008. «Educação pré-escolar: olhares do passado e do presente». Itinerários 7: 25-37.

Marchão, Amélia, e Alexandra Bento. 2012. «Promoção da igualdade de género - um estudo em contexto de educação pré-escolar». Comunicação apresentada no III Seminário de I\&DT, C3i, Instituto Politécnico de Portalegre, 6 e 7 de dezembro. Disponível em http://hdl.handle.net/10400.26/4117 [consultado em 1 setembro 2017].

ME - Ministério da Educação. 1979. «Decreto-Lei n. ${ }^{\circ}$ 542/79: Aprova o Estatuto dos Jardinsde-Infância», Diário da República, 300, 1. . Série, 12. ${ }^{\circ}$ Suplemento, de 31 de dezembro: 3478-(301) - 3478-(307). Disponível em https://dre.pt/application/file/82614

ME - Ministério da Educação. 1997. OCEPE - Orientações Curriculares para a Educação Pré-Escolar. Lisboa: Ministério da Educação.

Monteiro, Alcides, e Catarina Sales Oliveira. 2014. «Intervenção em igualdade de género no terceiro setor: organizações que discutem a sua própria mudança». Atas do VIII congresso da APS, 14 a 16 de abril, Universidade de Évora.

Ortiz, Paula (coord). 2010. Palmo e meio de igualdade. S.l.: Esdime - Agência para o Desenvolvimento Local no Alentejo Sudoeste. Disponível em https://www.esdime.pt/download/ged-3-002\%20palmo_e_meio_de_igualdade.pdf

Pereira, Maria do Mar. 2012. Fazendo género no recreio A negociação do género em espaço escolar. Lisboa: ICS.

Pires, Cristina. 2007. Educador de infância: teoria e práticas. Porto: Profedições.

Piscitelli, Adriana. 2009. "Gênero: a história de um conceito.»In: Diferenças, igualdade, organizado por Heloisa Buarque de Almeida e José Szwako. São Paulo: Berlendis \& Vertecchia.

Prates, Mónica, e Amélia Marchão. 2015. «Estudo das conceções de género presentes num jardim-de-infância da cidade da Ponte de Sor: as conceções das crianças, das educadoras e dos/as encarregados/as de educação». Aprender 36: 86-101. Disponível em http:// legado.esep.pt/aprender/index.php/revistas/116-revista-aprender-n-36

Ribeiro, Graça Barbosa. 2015. «Só 1\% dos educadores de infância são homens». Jornal Público, 26 de outubro. Disponível em https://www.publico.pt/2015/10/26/sociedade/ noticia/homens-ainda-so-representam-1-dos-educadores-de-infancia-1712313

Sales Oliveira, Catarina, Susana Vilas Boas, e Soledad Las Heras. 2016. «Estereótipos de género e sexismo em docentes do ensino superior». Revista Iberoamericana de Educación Superior 19(VII): 22-41. Disponível em https://ries.universia.net/article/view/1143/ estereotipos-genero-sexismo-em-docentes-do-ensino-superior 
Sarmento, Teresa. 2016. «Tempos de mudança na formação das educadoras e infância». Essentia - Revista de Cultura, Ciência e Tecnologia da UVA 17(1): 67-102. Disponível em http://www.uvanet.br/essentia/index.php/revistaessentia/article/view/94

Schouten, Maria Johanna. 2011. Uma sociologia de género. Vila Nova de Famalicão: Húmus.

Silva, Ana et al. 2005. A narrativa na promoção da igualdade de género: contributos para a educação pré-escolar. 3. ${ }^{\text {a }}$ edição. Lisboa: Comissão para a Igualdade e para os

Silva, Isabel Lopes (coord.), Liliana Marques, Lourdes Mata, e Manuela Rosa. 2016. Orientações Curriculares para a Educação Pré-Escolar. Lisboa: Ministério da Educação/DGE. Disponível em http://www.dge.mec.pt/ocepe/sites/default/files/Orientacoes_Curriculares.pdf

Vasconcelos, Teresa. 2007. «Aimportância da educação na construção da cidadania». Saber (e) Educar 12: 109-117. Disponível em http://repositorio.esepf.pt/bitstream/ 20.500.11796/ 714/2/SeE12A_ImportanciaTeresa.pdf

Vianna, Cláudia, e Daniela Finco. 2009. «Meninas e meninos na educação infantil: uma questão de gênero e poder». Cadernos Pagu 33: 266-283. DOI: https://doi.org/10.1590/ S0104-83332009000200010

Vieira, Cristina C. 2006. É menino ou menina? - Género e educação em contexto familiar. Coimbra: Almedina.

Vieira, Cristina C. 2013. Educação familiar: estratégias para a promoção da igualdade de género. Lisboa: CIG.

Catarina Sales Oliveira. Professora Auxiliar no Departamento de Sociologia da Universidade da Beira Interior (UBI), Portugal. Investigadora do Centro de Investigação e Estudos de Sociologia (CIES-IUL), Portugal. Tem como áreas de interesse os estudos de género, as organizações e a mobilidade especial e os transportes.

Endereço eletrónico: csbo@ubi.pt

Andreia Mendes. Licenciada e mestre em Sociologia pela Universidade da Beira Interior (UBI), Portugal.

Endereço eletrónico: andreia_222@sapo.pt

Artigo recebido a 31 de maio de 2017 e aceite para publicação a 01 de novembro de 2017. 